the obstacle to reduction was clearly this loose sling-like fold. The existence of membranous flaps like this and the manner in which they sometimes resist the return of the gut in operation for strangulated hernia have not of late received the attention they merit. Bands and flaps of this kind, which are not very rare, should invariably be divided whether they seem to compress the bowel or not, for if they do not actually prevent reduction it will be much more easily effected after their division. The history and mode of formation of these interesting folds may be conveniently reserved for consideration in another lecture.

\section{A CASE OF CEREBRO-SPINAL FEVER FOLLOWED BY RECOVERY.}

BY WM. ARMSTRONG, L.R.C.P., L.R.C.S. Edin., L.S.A.

I WAS called shortly after 6 A.M. on May 11th to see A. B- aged eleven years, who had been suddenly seized with intense pain in the head. The history of the case is as follows. On May 9th the patient was apparently well, and played football in a hot sun. After returning home he complained of feeling tired, and shortly after vomited bilious matter; he was hot and fererish. His mother, thinking he was bilious, administered a purgative draught. During the next day he remained in much the same condition, but on the following morning at 6 A.M. he was suddenly roused by a loud blast from a hooter, and at once complained of intense pain in the head, and became very restless and excited. I could obtain no history whatever of pain or discharge from either ear. On my seeing the patient he presented the following appearance. He lay on his back with his head on one side, the lower limbs being flexed on the abdomen. The face was flushed, conjunctivæ injected, pupils unequal, dilated, and sluggish, with great intolerance of light. Temperature $103 \cdot 8^{\circ}$, pulse 120 , very excited. On examining the chest, the heart was seen beating violently with a forcible impulse. The abdomen was rather retracted; no tenderness or pain on pressure ; no tympanites. No other abdominal symptoms. Slight diarrhoea, which was probably due to the purgative which had been administered. Tongue very furred in the centre and red at the edges. The patient kept crying out "Oh, dear !" in a very distressed way, and did not seem to understand questions put to him. He said that the worst pain was over the temples. He vomited green matter whilst I was there. By way of treatment, I ordered the head to be shaved and an ice-bag applied and prescribed three grains of calomel and a mixture containing five-grain doses of bromide of potassium, the diet to be milk with soda-water or lime-water. During the first week the temperature ranged between $101^{\circ}$ and $104^{\circ}$ and the pulse between 108 and 120 . The headache was much the same, but considerably relieved after each dose of medicine. The patient complained of pain in the back of the neck, down the spine, in the arms and at the pit of the stomach. The position he assumed was one of partial flexion; the head was thrown well back and there was marked stiffness of the neck. There was also marked hyperæsthesia all over the body. The tongue remained very furred; bowels rather constipated; there was no enlargement of the spleen. He continued very restless and delirious, at times being in a condition of stupor. There was great intolerance of light; sluggish pupils with strabismus of the left eye. A large quantity of pale urine was passed. The lower lobes of both lungs became congested. During the second week the patient improved a little and took nourishment well. There was now marked retraction of the abdomen. As he passed very wakeful restless nights I prescribed a draught containing fifteen grains of bromide of potassium and five grains of chloral hydrate with success. Temperature about $102^{\circ}$. At the end of the third week the temperature fell to normal; pulse 80 bowels constipated; there was a good deal of pain in the hips, down the spine, in each leg and also in the neck; a small mustard poultice placed behind the ear relieved the latter ; general condition improving; diplopia and strabismus nccasionally present. On May 30th the patient became very much worse. Temperature $104 \cdot 8^{\circ}$; pulse 120 . Herpes round the mouth, with sordes on the teeth and tongue; the latter was very dirty looking. He vomited, complained of his head, and lay in a stupor. As an error in diet was traced I ordered a tablespoonful of castor-oil, and on June 1st he was much better, with a normal temperature. After this the improve. ment continued. The appetite was very good. He occasionally complained of frontal headache, but there were no other pains. The intolerance of light gradually lessened, but diplopia of the left eye was present until June 8th. Ordered to have a farinaceous diet with a little fish. - June 10th: Patient very much improved; convalescence rapidly advanced. July 9th: Went away to the seaside, apparently quite well,

hemarks. - The patient is said to have lost a sister aged four years of acute meningitis, death taking place in twentysix hours; the supposed cause was a chill. There is no tubercular history on either side of the family. During the whole of the present attack careful examination failed to detect any sign of pulmonary tuberculosis. The patient is an intelligent, precocious lad, very fond of books. Last Decem. ber, whilst on a visit at Congleton, he had an attack of illness, in which the following symptoms were present: frontal headache, vomiting, constipation, fever, with loss of appetite for seven days. The case was diagnosed by the medical man as "slow fever." With respect to the term of "diplopia of the left eye" used in the description of the case, the following are the facts. When the left eye was closed vision was normal ; when the right eye was closed the patient said he saw two doctors or two mothers with the left eye.

Pontesbury, Salop.

\section{THE CONDITION OF TWENTY-FOUR CASES OF EMPYEMA IN CHILDREN AFTER CURE BY RESECTION OF RIB.}

BY E. B. HASTINGS, M.D. LOND., LATE RESIDENT MEDICAL OFFICER TO THE EAST LONDON HOSPITAL FOR CHILDREN, SHADWELL

AND

HARFORD N. EDWARDS, M.R.C.S., L.R.C.P. LOND. LATE HOUSE PHYSICIAN TO THE EAST LONDON HOSPITAL FOR CHILDREY, SHADWELL.

THE operation of resection of a portion of a rib, with free drainage of the pleural cavity, is one now generally performed in empyema after other treatment has failed; but the ultimate results of the operation as regards deformity, \&c., are. not well known, because the patients are not, as a rule, kept under observation after the wound has healed, although there are still abnormal physical signs in all cases. With the view of ascertaining what is the condition of cases of empyema in children after a considerable period has elapsed. from the date of discharge from hospital, we have examined as many old patients of the East London Hospital for Children as were accessible. All the patients in the hospital books for the last eight years have been written for, but the great majority having changed their residences since leaving the hospital the letters addressed to them have been returned undelivered. In a few other cases no notice was taken, although the letters were apparently delivered. We have been able to examine 24 cases, all of whom had had a portion of one rib excised, and notes of their present condition are given below. The following figures show the periods which have elapsed since the operations were performed: Seven years in 2 cases, four to five in 4 cases, three to four in 2 cases, two to three in 7 cases, one to two in 6 cases, and less than one year in 3 cases. The ages of the patients at the time of operation were as follows: One year in 2 cases, two years in 6 cases, three in 2 cases, four in 3 cases, five in 3 cases, six in 3 cases, seven in 1 case, eight in 1 case, nine in 2 cases, thirteen in 1 case.

The causation of the empyema is in most of our cases doubtful, the patients having been brought to the hospital only when the disease had reached a more or less chronic stage; but it is stated to have been the result of pleuro-pneumonia in some of them, and it was probably a sequela of this disease in most cases. It is difficult to obtain an accurate account of symptoms, as most of the children are too young to give a statement of their own symptoms and their mothers are either unobservant or, being at work all day, ignorant of them. It is impossible to get an account of the symptoms without putting leading questions, and the description of them must therefore be taken with some reserve. There was pain in the affected side in two cases, but only occasionally. In eight there was a history of cough, but in only one was it stated that the cough was serere 